\title{
PARENTAL NUTRITION MODEL AND CHILDREN'S NUTRITIONAL BEHAVIOURS
}

\author{
Sepideh Taghizad Banaei ${ }^{1}$,Akram Peyman², Mohammad Eslami Vaghar ${ }^{3}$
}

1 Master of Nursing, Department of Nursing, Tehran Medical Sciences, Islamic Azad University, Tehran, Iran.

${ }^{2}$ Faculty of Nursing and Midwifery, Department of Midwifery, Tehran Medical Sciences, Islamic Azad University, Tehran, Iran. ${ }^{3}$ Faculty of Nursing and Midwifery, Department of Midwifery, Tehran Medical Sciences, Islamic Azad University, Tehran, Iran.

\section{ABSTRACT}

\section{BACKGROUND}

Human beings need nutrition to maintain their vitality and health. Today's life has affected and mostly disturbed people's dietary habits, causing various anomalies and diseases in their bodies. So, humans need to reform their diet and nutrition. The best way to do this is to improve the child's nutritional habits.

\section{MATERIALS AND METHODS}

The present descriptive-correlational study was conducted on children aged 7 - 12 years in non-governmental schools in Tabriz in 2017. Out of each educational district of Tabriz, two segregated schools for boys and girls were selected, making up a total of ten schools and all stages of selecting schools and students were determined by random sampling. The research population includes the parents of those children studying in these schools who were selected through cluster sampling; required data was collected using questionnaires responded to by parents.

\section{RESULTS}

Findings showed that there is a logical and positive relationship between parental nutrition model and two components of the child nutritional behaviour including "accepting food" and "enjoying food." But the other two components, "food complaints" and "refusal to eat" turned out to be significantly lower than the average indicating a logical and inverse relationship.

\section{CONCLUSION}

Given the fact that the majority of the children are sheltered and brought up by the family as well as the role of parental nutritional model in following the best example for the children, parents can select the appropriate nutritional behaviours and create a proper nourishing pattern which reduces children's mistakes in food, increases their acceptance and satisfaction with food and ensures proper growth to guarantee health and vitality for the future of children.

\section{KEY WORDS}

Nutrition; Nutritional Behaviours; Children.

HOW TO CITE THIS ARTICLE: Banaei ST, Peyman A, Vaghar ME. Parental nutrition model and children's nutritional behaviours. J. Evolution Med. Dent. Sci. 2018;7(43):4599-4602, DOI: 10.14260/jemds/2018/1026

\section{BACKGROUND}

Humans require nutrition throughout their lives in order to continue to live. This has a significant impact on mental health. In addition, other factors such as psychological needs, also contribute to eating. Thus, eating plays an important role in the mental and physical health of an individual.[1]

However, nutrition should go, as in any other case according to the rules and regulations. Nowadays, incorrect nutrition practices such as constant food availability, cheap and tasteful food, high energy intake, low levels of nutrients and lifestyles that go hand-in-hand, are all factors that cause severe problems, diseases, cancers and other problems including obesity and its pathogenic effects on the body in modern life.[2]

Overweight and obesity as well as diseases associated with them are largely preventable.

'Financial or Other Competing Interest': None.

Submission 25-09-2018, Peer Review 08-10-2018,

Acceptance 10-10-2018, Published 22-10-2018.

Corresponding Author:

Dr. Akram Peyman,

Department of Midwifery,

Faculty of Nursing and Midwifery,

Tehran Medical Sciences,

Islamic Azad University, Tehran, Iran.

E-mail: akrampeyman@yahoo.com

DOI: $10.14260 /$ jemds/2018/1026
Therefore, prevention of childhood obesity is one of the priorities. According to WHO reports, the prevalence of overweight and obesity worldwide has risen from 4.2 percent in 1990 to 6.7 percent in 2010 and this trend is expected to reach $9.1 \%$ (60) million in 2020 . More than $30 \%$ of children in the Eastern countries are obese. In the United Arab Emirates, this percentage is $16.6 \%$ among young people.[3] Overweight and obesity in children aged $6-16$ years has increased upto $1.8 \%$ in the United States.[4] Health professionals are nowadays worried about malformed eating habits that led to weight loss, inappropriate body image and many illnesses.

Therefore, the first step is to change nutritional habits and adopt right nutrition practices to prevent such problems and diseases. It is important to note that the behaviour and habits that form in childhood persists throughout the life of an individual, providing further proof for the importance of the issue under study. Thus, it can be claimed that changing the nutritional pattern of children will deliver healthy adults to the community. But how? What factors affect the nutrition and nutritional behaviour of children? According to many studies conducted in this field, a large part of the child's food preferences is formed in the family environment under the supervision of parents.[5] Parents can have a direct impact on their child's body mass with a nutrition pattern that runs at home. Food behaviours in childhood are directly related to weight in school and adulthood.[6] 
The children are mostly influenced by their parents in the early years of human life, although the impact of the peer group and the media cannot be ignored. Parents, as the only model and legislator, have the ability to form good food habits or sometimes "cause the formation of bad eating habits in their children." The majority of nutritional behaviours and habits of a child forms within the circle of family, because he sees what his parents do and learns such behaviours. Parents' behaviours and actions in the family environment will affect the physical condition of the child including the child's diet and this is also very prominent. The effect of parents on their child's dietary habits is more significant during childhood, and as their child grows up the influence of home becomes less and less. ${ }^{[7]}$

There is a positive relationship between the emotional eating of children and nutritional and emotional aspects with the negative relationship between nutrition and emotional control. The result of this study showed that maternal nutritional practices play an important role in the development of children. ${ }^{[8]}$ In a similar study, Sadoughi asks families to focus on providing proper models for their children, as children follow what we do rather than what we say.[9] Another study suggests that nutritional method of parents has a positive effect on the BMI of children. [10]

Given what has been stated so far and the importance of the issue, the researcher has tried to investigate the effects of nutritional model of parents on the nutritional behaviour of children. Therefore, students in primary schools of Tabriz city have been selected as study population.

\section{MATERIALS AND METHODS}

The present descriptive correlation study assesses the effect of parental nutrition model on nutritional behaviour of $7-12$ year-old children studying in non-profit schools in Tabriz city. Tabriz has a total of 5 education districts. Two schools are selected for boys and girls, and all stages of selection of schools and students are conducted by random sampling.

The research population includes the parents of those children studying in these schools, who were selected through cluster sampling. Initially, qualified schools within specific districts were selected. Then, the required students from each school were identified by simple random sampling method to participate in the study and required data was collected through questionnaires completed by the parents of the selected students. The sample size according to the Cochran formula as indicated below, is specified at a confidence level of $5 \%$ alpha. In this formula, $\mathrm{Z2}$ is equal to $0.84, p$ and $q$ is 0.5 , d, with error level of $5 \%$, is equal to 0.05 , and $\mathrm{N}$ which is related to the number of statistical population is equal to 600 .

$$
n=\frac{\frac{z^{2} p q}{d^{2}}}{1+\frac{1}{N}\left(\frac{z^{2} p q}{d^{2}}-1\right)}
$$

According to the above formula, the sample size was 235 people. In order to prevent the loss of the questionnaires, 252 questionnaires were finally used for statistical analysis.

\section{The Main Inclusion Criteria are like the Following-}

1. Parents must be in charge of feeding the children.
2. The child's parents must live together and this fact should be confirmed by school officials.

3. Children, according to parents and children's health records at school should be healthy and have no physical or mental health problems.

The CEB questionnaire, which is a tool with 35 questions for assessing the dimensions of the baby's eating style, assessed 5 components of "responding and accepting food," "enjoying food," "early satiety," "eating slowly" and "find mistakes with food." The impact of parents' eating model on children's nutritional habits was assessed by three questions written by Gregory.[11]

These questions are in the field of modelling for healthy eating-

A. I try to eat healthy food in front of my child.

B. My baby always sees me eating healthy food.

C. My child always sees me eating healthy snacks.

Cronbach's alpha coefficient was used to assess the reliability of the scale. After obtaining the license from the Faculty of Nursing and Midwifery of Islamic Azad University of Tehran and Tabriz Educational Centre and its related schools, the questionnaires were delivered to parents of selected children.

\section{Statistical Analysis}

The questionnaires were analysed using SPSS software version 20. This is a descriptive correlation study and descriptive statistics (for preparing the required tables, percentage, mean and the standard deviation of the samples) were used for describing the data. Moreover, inferential statistical tests (Pearson's correlation test for finding the relationship between children's nutritional behaviour and parents' controlling strategies) were used for data analysis.

\section{RESULTS}

\section{Findings}

Of the total 252 participants in the study, 146 were males and 106 were females. The majority of participants, $33.3 \%$ or one-third of the participants were 9 years old; $30.2 \%$ of subjects were 8 years old, $20.6 \%$ were 10 years, $9.5 \%$ were 7 years, $6 \%$ were 11 years and only $1 \%$ were 12 years old.

\section{Studying the Nutritional Behaviours of Children}

With a mean of 46.03, responsiveness and food acceptance turned out to be higher than other components, indicating that children are more likely to use this method and dietary behaviour. Also, with a mean of 2.83 and SD of 0.55 , finding mistakes with food turned out to be the weakest component (Table 1).

\begin{tabular}{|c|c|c|c|c|c|}
\hline $\begin{array}{c}\text { Under } \\
\text { Analysis } \\
\text { Criteria }\end{array}$ & $\begin{array}{c}\text { Finding } \\
\text { Mistakes } \\
\text { with } \\
\text { Food }\end{array}$ & $\begin{array}{c}\text { Early } \\
\text { Satiety }\end{array}$ & $\begin{array}{c}\text { Enjoying } \\
\text { Food }\end{array}$ & $\begin{array}{c}\text { Refusing } \\
\text { to Eat }\end{array}$ & $\begin{array}{c}\text { Accepting } \\
\text { Food }\end{array}$ \\
\hline Mean & 2.83 & 11.03 & 33.03 & 2.96 & 46.03 \\
\hline SD & 0.552 & 0.514 & 0.701 & 0.038 & 0.690 \\
\hline Variance & 0.304 & 0.264 & 0.491 & 0.001 & 0.476 \\
\hline Min & 1.23 & 2.12 & 1.83 & 2.83 & 1.98 \\
\hline Max & 4.11 & 4.56 & 3.90 & 3.80 & 4.65 \\
\hline \multicolumn{6}{|c|}{ Table 1. Food Behavioural Components of Children } \\
Participating in the Study \\
\hline
\end{tabular}




\begin{tabular}{|c|c|}
\hline Under Analysis Criteria & Modelling Role \\
\hline Mean & 0.386 \\
\hline SD & 0.622 \\
\hline Variance & 0.386 \\
\hline Min & 2.01 \\
\hline Max & 4.11 \\
\hline $\begin{array}{c}\text { Table 2. The Results of different Tests in regard with the } \\
\text { Modelling Role of Parents' Nutritional Style }\end{array}$ \\
\hline
\end{tabular}

The relationship between modelling role of parental nutrition and children's eating behaviours

The results show that there is a positive and significant relationship between modelling role of parental nutrition and accepting food by children in the level of less than 0.05 ; however, there is a negative and significant relationship between modelling role of parental nutrition and finding mistakes with the food by the child, thus indicating the reverse relationship and reducing the objection in case of high and more effective parenting modelling. There is also a positive and significant relationship between modelling role of parental nutrition and responsiveness and acceptance components of food by the child at a level less than 0.05 (Table 3).

\begin{tabular}{|c|c|c|}
\hline $\begin{array}{c}\text { Criteria of Nutritional } \\
\text { Behaviour of Children }\end{array}$ & Tests & $\begin{array}{c}\text { Parents' Nutritional } \\
\text { Behaviour as Model }\end{array}$ \\
\hline $\begin{array}{c}\text { Finding mistake with } \\
\text { food }\end{array}$ & $\begin{array}{c}\text { Significance } \\
\text { level }\end{array}$ & $\mathrm{P}<0 / 05$ \\
\cline { 2 - 3 } Early satiety & $\begin{array}{c}\text { Correlation } \\
\text { Significance } \\
\text { level }\end{array}$ & 0.388 \\
\cline { 2 - 3 } & Correlation & $\mathrm{P}=0.80$ \\
\hline \multirow{2}{*}{ Enjoying food } & $\begin{array}{c}\text { Significance } \\
\text { level }\end{array}$ & 0.340 \\
\cline { 2 - 3 } & Correlation & $\mathrm{P}=0.11$ \\
\hline \multirow{2}{*}{$\begin{array}{c}\text { Refusing to eat } \\
\text { Significance } \\
\text { level }\end{array}$} & 0.300 \\
\cline { 2 - 3 } & Correlation & $\mathrm{P}=0.39$ \\
\hline \multirow{2}{*}{$\begin{array}{c}\text { Accepting food } \\
\text { Significance } \\
\text { level }\end{array}$} & 0.310 \\
\cline { 2 - 3 } & Correlation & $\mathrm{P}=0.63$ \\
\hline Table 3. Correlation Test between Child's Nutritional \\
Behaviours and Parental Nutrition Model
\end{tabular}

\section{DISCUSSION}

To survive, humans need to maintain nutrition throughout their life, since this factor exerts a significant effect on individuals' mental health. Behaviours and habits that form in childhood remain with the individual throughout his life.[9] Therefore, paying specific attention to nutrition is important from childhood; on the other hand, parents can have a direct impact on their child's body mass index by forming an efficient nutritional model.[6] In addition to health and other dimensions of life, paying attention to the nutrition of a child is also effective in improving educational and behavioural conditions. ${ }^{[12]}$ Children need adequate nutrition and physical activity in order to achieve sufficient physical and mental development and can also cope with chronic diseases that might develop.[13] Therefore, forming useful nutritional behaviours during childhood and puberty is one of the main causes of physical growth.[14]

As the most important social unit throughout history, family has played a major role in creating a healthy, innovative and dynamic society; additionally, all divine religions have emphasised the formation of families, family management and upbringing virtuous children, because family has the closest contact with the child during growing years and it plays an important role in determining the patterns of behaviour a child might adopt later in life. One of the most important responsibilities of parents is providing efficient models of nutrition for their children, a model which functions efficiently, because as most scholars have emphasised bad behaviour and eating habits develop since childhood. Thus, parents should be very careful about their behaviours, because children imitate and follow what they do. On the other hand, the present study showed that parents take more advantage of their role as models for nutrition behaviours of their children. This recognition can be attributed to attempts which have been implemented to enhance the awareness and public knowledge in this regard in regards with the role and importance of parents in schools or health centres. This had made parents quite careful in functioning as proper models. In a research that was consistent with this specific finding of the present study, Sadoughi emphasised the role of parents as a model for forming nutritional behaviour in children. They stated that patterns upon which family is based play the most important role during the life of an individual and according to it it is quite natural to expect a child to imitate the behaviour of parents.[9] Lindquist et al study in 2002 showed that childfriendly nutrition method has a positive effect on the physique of children, which shows the effect of the parental pattern on the responsiveness and acceptance of food by the child.[10] They also showed that maternal nutritional practices play an important role in the development and obesity of children.[8]

Another dimension of the present study showed that there is a negative relationship between modelling role of parents and family and the component of finding mistake with food by the child, indicating the reciprocity of the relationship and the reduction of objections in case of high and more effective modelling role by parents. Ostbye's study also confirmed that family plays a major role in shaping the baby's eating habits before the child goes to school.[15] Contrary to popular belief, children will never have the congenital ability to choose a balanced and nutritious diet, and they choose only what they provided with. Therefore, parents and adults are responsible for providing such nutritious foods for the child. Children imitate and follow what their parents do. Parents' participation in positive affairs and showing healthy behaviours on their behalf is the best educational method for children.[16]

\section{CONCLUSION}

In general, it can be concluded that the family's nutritional habits have an impact on the diet of the child and can lead to inappropriate selection of nutrition and educational practices by the parents might lead to nutritional problems in the future of the child. Therefore, it can be argued that there is a relationship between the modelling role of family pattern and two components of responsiveness and accepting food by the child. Given the modelling role of parents as the best example for the children, parents can choose their nutritional behaviours and form a proper model of nutrition that can reduce children's mistakes in food, increase their acceptance of food and ensure the growth and well-being of children. 
The adoption of healthy food practices by parents can affect the child's dietary patterns and reduce the problems of eating and malnourishment. Therefore, this research recommends parents to receive appropriate nutritional behaviours based on scientific and methodological approaches in order to have a positive effect on their children.

There are also other factors that can be taken advantage of in the absence of proper modelling of families and parents, including social issues, peer groups and media outlets and social networks. The form of families has changed in recent years and the majority of parents work outside. Thus, many children might eat at least one meal outdoors. On the other hand, the consumption of ready and semi-ready foods has increased, which has led to the emergence of unsuitable food patterns for children. Therefore, it is recommended to investigate the effects of other factors, such as peer group and social media, on the dietary habits of children in further studies.

\section{REFERENCES}

[1] Reeve JM. Understanding motivation and emotion. John Wiley \& Sons 2014: p. 50-200.

[2] Crouch P, O'DEA JA, Battisti R, et al. Child feeding practices and perceptions of childhood overweight and childhood obesity risk among mothers of preschool children. Nutrition \& Dietetics 2007;64(3):151-8.

[3] Stott K. Teacher, parents and student's perception of childhood obesity in the Middle East. Al Qasimi Foundation for Policy Research 2008;2:18-38.

[4] Al-Haddad F, Al-Nuaimi Y, Little BB, et al. Prevalence of obesity among school children in the United Arab Emirates. American Journal of Human Biology: The Official Journal of the Human Biology Association 2000;12(4):498-502.

[5] Scaglioni S, Salvioni M, Galimberti C. Influence of parental attitudes in the development of children eating behaviour. British Journal of Nutrition 2008;99(Suppl 1):S22-S5.

[6] Alinaghizadeh E, Javadi M, Agha APH, et al. Predicting factors associated with healthy eating nutritional behavior at primary school students in Tehran: an application of the Health Action Process Approach (HAPA). Iranian Journal of Endocrinology and Metabolism 2017;19(4):252-60.
[7] Johnson SL, Birch LL. Parents' and children's adiposity and eating style. Pediatrics 1994;94(5):65361.

[8] Rodgers RF, Paxton SJ, Massey R, et al. Maternal feeding practices predict weight gain and obesogenic eating behaviors in young children: a prospective study. International Journal of Behavioral Nutrition and Physical Activity 2013;10:24.

[9] Behnam S. A survey on the relationship between the child's developmental status and the nutritional behavior of mothers of 3-6 year-old children referring to Qazvin health centers. Master's thesis, Qazvi University of Medical Sciences/Qazvin/ Iran 2017: P. 20-74.

[10] Spruijt-Metz D, Lindquist CH, Birch LL, et al. Relation between mothers' child-feeding practices and children's adiposity. The American Journal of Clinical Nutrition 2002;75(3):581-6.

[11] Gregory JE, Paxton SJ, Brozovic AM, et al. Maternal feeding practices, child eating behaviour and body mass index in preschool-aged children: a prospective analysis. International Journal of Behavioral Nutrition and Physical Activity 2010;7(1):55.

[12] Mostaghimi H, Djazayery A, jazayeri S, et al. Dietary patterns and executive functions in 6-8 years old children. Iranian Journal of Nutrition Sciences \& Food Technology 2018;12(4):13-24.

[13] Baygi F, Qorbani M, Dorosty AR, et al. Dietary predictors of childhood obesity in a representative sample of children in north east of Iran. Zhongguo Dang Dai Er Ke Za Zhi Chinese Journal of Contemporary Pediatrics 2013;15(7):501-8.

[14] Koochakpour G, Hosseini-Esfahan F, Bahadoran Z, et al. Food patterns of Tehranian adolescents and their relation to anthropometric measures and blood pressure: Tehran lipid and glucose study. Iranian Journal of Endocrinology and Metabolism 2012;14(1):1-9.

[15] Ostbye T, Malhotra R, Stroo M, et al. The effect of the home environment on physical activity and dietary intake in preschool children. International Journal of Obesity (Lond) 2013;37(10):1314-21.

[16] Dwivedi C, Chandrakar K, Singh V. Indian herbal medicines used for treatment of dementia: an overview. International Journal of Pharmacognosy 2014;1(9):353-71. 